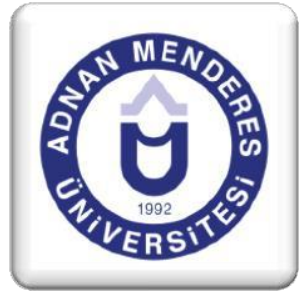

\title{
Ăgaç ve Ăgaç Mamulleri Endüstrisinin İhracat Performansının İncelenmesi: Nordik Ülkeleri Örneği
}

\author{
Güçgeldi BASHIMOV ${ }^{1}$
}

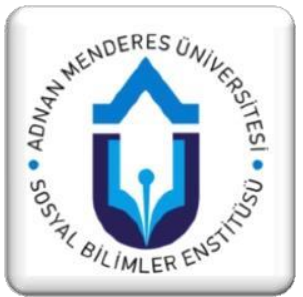

Özet

Ağaç ve ağaç mamulleri endüstrisi Nordik ekonomilerinin önemli bir sanayi dalını oluşturmakta ve bu sanayi dalı Nordik ülkelerinin dış ticaretinde ve ekonomik kalkınmasında önemli rol oynamaktadır. Son 15 yıllık dönemde Nordik ülkelerinin ağaç ve ağaç ürünleri ihracatı \%35 oranında bir artış göstermiştir. Bugün, Nordik ülkeleri birçok ağaç ürünlerinin üreticisi ve aynı zamanda ihracatçısıdır. Bu çalışmada Nordik ülkelerinin (Danimarka, İsveç, Norveç, Finlandiya ve İzlanda) ağaç ve ağaç ürünleri endüstrisinin ihracat performansı analiz edilmiştir. $\mathrm{Bu}$ amaçla çalışmada Açıklanmış Karşılaştırmalı Üstünlükler (AKÜ), Açıklanmış Simetrik Karşılaştırmalı Üstünlükler (ASKÜ) ve Ticaret Dengesi İndeksinden yararlanılmıştır. Çalışmada Armonize Mal Tanım ve Kodlama Sisteminin (HS) iki basamaklı sınıflandırması kullanılmıştır. Analiz aşamasında 2001-2015 dönemine ait BM COMTRADE verileri kullanılmıştır. Araştırma sonucuna göre, Danimarka, Finlandiya ve İsveç ağaç ve ağaç ürünlerinde rekabet gücüne sahipken, Norveç ve İzlanda ise rekabet dezavantajına sahiptir. Ayrıca, Finlandiya ile İsveç ağaç ve ağaç ürünlerinde net ihracatçı konumda iken, Danimarka, Norveç ve İzlanda ise net ithalatçı ülkeler konumundadır.

Anahtar Kelimeler: Nordik ülkeleri, Ağaç ürünleri, Rekabet gücü

\section{Assessing The Export Performance of Wood and Articles of Wood Industry: The Case of Nordic Countries}

\begin{abstract}
Wood and articles of wood industry is one of the key industries of Nordic economies. It is plays an important role in Nordic countries foreign trade and economic development. In the last 15 years, the export of wood and articles of wood has grown 35 percent. Today, Nordic countries are major producer and exporter of many wood based products. In this study examined the export performance of wood and articles of wood industry of Nordic countries (Denmark, Sweden, Norway, Finland and Iceland). With this aim, the Revealed Comparative Advantage (RCA), Revealed Symmetric Comparative Advantage (RSCA) and Trade Balance Index were used. The study used 2 digit level of Harmonized Commodity Description and Coding System (HS) classification. In study used UN COMTRADE statistical data for the period 2001-2015. According to the findings Denmark, Finland and Sweden have the competitiveness in the wood and articles of wood. It was found that Norway and Iceland have the competitive disadvantage in the wood and articles of wood. Also, it was found that Finland and Sweden are net exporters in wood and articles wood while Denmark, Norway and Iceland are net importer countries in wood and articles of wood.
\end{abstract}

Key Words: Nordic countries, Wood products, Competitiveness

\footnotetext{
${ }^{1}$ Niğde Ömer Haisdemir Üniversitesi SBE Doktora Öğrencisi, Niğde, guyc55@gmail.com
} 


\section{Giriş}

Dünyadaki hızlı nüfus artışı ve sanayileşme doğal kaynaklar üzerinde yoğun baskılar oluşturmakta ve bu olumsuzluktan ormanlar ciddi şekilde etkilenmektedir. İnsan yaşamı için gerekli olan ihtiyaç maddelerinin büyük bir çoğunluğu ormanlardan sağlanmaktadır. Diğer sektörleri besleyen temel girdi olarak önemli bir yere sahip olması sebebiyle orman ve orman ürünleri, ülkelerin ekonomik kalkınmalarında son derece önemli bir yere sahiptirler (Ekti, 2013). XX. Yüzyılın başlarından itibaren gelişmeye başlayan orman ürünleri sanayisi özellikle II. Dünya Savaşı sonrası dönemde daha da hızlı bir gelişme göstermiş ve bugünkü düzeye ulaşmıştır. Gelişen teknoloji ile birlikte orman ürünlerinden faydalanmada çok yönlülük kazanmış ve odunun kullanım yeri günümüzde 6.000'e ulaşmıştır (Yıldırım, 2006).

Orman ürünleri sanayisi ekonomiye sağladığı katkılarından dolayı Nordik ekonomileri (Danimarka, İzlanda, Finlandiya, İsveç ve Norveç) için de stratejik bir öneme sahip sektörlerin başında gelmektedir. Orman ürünleri sanayisi, sağladığ 1 katma değer, istihdam ve ihracat imkânları nedeniyle Nordik ülkelerinin ekonomik kalkınmasında önemli rol oynayan bir sanayi dalıdır. Bu çalışmada, Nordik ülkelerinin 2001-2015 dönemi için ağaç ve ağaç ürünleri sanayisinin alt sektörü olan ağaç ve ağaç mamulleri ihracatındaki karşı̧laştırmalı üstünlüğü analiz edilmiştir. Nordik ülkelerinin ağaç ve ağaç mamulleri üretimi bakımından yüksek potansiyele sahip olması, sektörün ulusal ekonomiye ve ihracata sağladığı katkısı nedeni ile araştırmaya değer olarak görülmüştür.

\section{Literatür Araştırması}

Bugüne kadar çeşitli ülkelerde orman ürünleri sanayisinin rekabet gücünü ölçmek için çok sayıda çalışma yapılmıştır. Bu çalışmaların önemli bir kısmı ise Açıklanmış Karşılaştırmalı Üstünlükler indeksi kullanılarak yapılan çalışmalardır. Bu bölümde söz konusu çalışmaların bazıları hakkında kısa bilgiler sunulmaktadır.

Gonuguntla (2007). Yeni Zelanda'nın orman ürünlerindeki rekabetçilik düzeyi seçilmiş bazı ülkeler ile karşılaştırmalı olarak analiz edilmiştir. Çalışmada Balassa tarafindan geliştirilen Açıklanmış Karşılaştırmalı Üstünlük indeksi kullanılmıştır. Sonuç olarak, Yeni Zelanda'nın orman ürünleri ihracatında rekabet gücüne sahip olduğu belirlenmiştir. Ayrıca, Yeni Zelanda'nın Kanada ve Rusya'ya kıyasla daha yüksek rekabet gücüne sahip olduğu saptanmıştır.

İbrahim ve ark. (2008). Türkiye odun esaslı levha endüstrisinin AB ülkeleri ile rekabet edebilirliği araştırılmıştır. Çalışmada Aşamalı Kümeleme Analizi ile Ayırma Analizi yöntemleri kullanılmıştır. Sonuç olarak, Almanya ile Fransa'nın odun esaslı levha endüstrisinde diğer ülkelere göre önemli bir üstünlüğe sahip olduğu belirlenmiştir. Bununla birlikte, Türkiye, İngiltere, Polonya, İspanya, İtalya, Belçika ve Avusturya'nın odun esaslı levha üretim ve ihracatında önemli bir yere sahip oldukları belirtilmiştir.

Aini ve ark. (2010). Malezya orman ürünleri sanayi sektörünün Avrupa pazarındaki rekabet gücü analiz edilmiştir. Rekabet gücünün ölçümünde Balassa tarafından geliştirilen 
Açıklanmış Karşılaştırmalı Üstünlükler indeksi kullanılmıştır. Elde edilen bulgulara göre, Malezya Avrupa pazarında rekabet gücüne sahiptir.

Müftüoğlu (2011). Standart Uluslararası Ticaret Sinıflandırması (SITC Rev.3) dikkate alınarak Türkiye'de ormana dayalı sektörlerin dış ticaretteki rekabet gücü incelenmiştir. Analiz sonucunda ormana dayalı sektörler içerisinde yer alan mobilya sektörünün rekabet gücüne sahip olduğu ve bu durumun önümüzdeki y1llarda da devam edeceği saptanmıştır. Ormana dayalı sektörler içerisinde yer alan odun ve kereste, ahşap eşya, kâğıt ve karton alt sektörlerinin ise rekabet gücüne sahip olmadığı belirlenmiştir.

Bashimov (2015). 2001-2013 dönemi için Rusya orman ürünleri sanayisinin rekabet gücü analiz edilmiştir. Çalışmada Açıklanmış Karşılaştırmalı Üstünlükler ve Net Ticaret İndeksi kullanılmıştır. Sonuç olarak, Rusya'nın orman ürünleri sanayisinde rekabet gücüne sahip olduğu belirlenmiştir. Ancak, son yıllarda rekabet gücünün zayıfladığı tespit edilmiştir.

Maksymets ve Lönnstedt (2015). Çalışmada 1995-2001 dönemi için ABD, İsviçre, Ukrayna ve Çin'in ormana dayalı ürünlerdeki rekabet gücü incelenmiştir. Çalışmada İhracat Piyasa Payı İndeksi, İhracat Yoğunlaşma İndeksi ve Ticaret Dengesi İndeksi kullanılmıştır. Sonuç olarak, söz konusu ülkelerin dünya orman ürünleri ticaretinde rekabet gücüne sahip oldukları belirlenmiştir.

Palus ve ark. (2015). Slovakya'nın orman ürünleri sektöründeki rekabet gücü analiz edilmiştir. Çalışmada İhracat-İthalat Oranı, Açıklanmış Karşılaştırmalı Üstünlükler indeksi, Açıklanmış Simetrik Karşılaştırmalı Üstünlükler indeksi, Açıklanmış Rekabet Gücü indeksi ve Grubel-Lloyd indeksi kullanılmıştır. Araştırma sonucunda Slovakya'nın orman ürünlerinde rekabet gücüne sahip olduğu belirlenmiştir. Ayrıca, ormana dayalı ürünlerin ticaretinde endüstri-içi ticaret düzeyinin yüksek olduğu saptanmıştır.

\section{Rekabet Gücü: Kavramsal Çerçeve}

Günümüzde uluslararası ihracat pazarlarını ele geçirebilmek, bu pazarlarda tutunabilmek veya pazar payını artırabilmek için ülkeler arasında amansız bir yarış vardır. Bu yarışta başarılı olabilmenin temel koşulu ise yüksek bir rekabet gücüne sahip olmaktır (Seyidoğlu, 2015). Dolayısıyla, gerek yerli ve gerekse yabancı literatürde rekabet ve rekabet gücü ile ilgili yapılan çalışmalar oldukça önem kazanmış bulunmaktadır (Saraçoğlu ve Köse, 2000).

Rekabet gücü kavramının herkesçe kabul edilmiş bir tanımı bulunmamaktadır. Bugüne kadar rekabet kavramı ekonomistler, politikacılar ve akademisyenler tarafindan farklı şekillerde tanımlanmıştır. Dolayısıyla her araştırmacı rekabet gücü konusunu kendi uzmanlık alanı çerçevesinde ele almış ve konuya bu açıdan yorum getirmişlerdir. Genel olarak rekabet gücü firma, sektör veya uluslararası düzeyde ele alınmıştır. Rekabet gücü çok genel anlamda, "bir ülkenin ürettiği bir ürünü dünya fiyatlarından dünya piyasalarında satabilme, uluslararası pazarda etkili bir ihracat payına sahip olabilme ve bu konumunu devam ettirebilme gücü” olarak tanımlanabilmektedir (Saraçoğlu ve Köse, 2000). 
Rekabet gücü firmalar açısından, arz etmiş oldukları mal ve hizmetlerin alternatifleri karşısında tercih edilmesini sürdürülebilir olarak sağlayan bir yetenek olarak tanımlanmaktadır (Çoban, 2001). Başka bir tanıma göre rekabet gücü, bir endüstrinin rakiplerine eşit ya da daha üst düzeyde bir verimlilik düzeyine ulaşması ve bu verimlilik düzeyini devam ettirmesi ve üretmiş olduğu ürünleri, rakiplerinin maliyetlerine eşit ya da daha düşük maliyette üretme ve satabilme yetisine sahip olmasıdır (Markusen, 1992). Diğer bir tanıma göre rekabet gücü, bir ülkenin ürettiği mallarda diğer ülkelerin malları ile fiyat, kalite, tasarım, güvenilirlik ve zamanında teslim gibi unsurlarda yarışabilir düzeyde olmasıdır (Kelleci, 2009). Ketels ise rekabet gücünü, uluslararası piyasalarda satış yapabilme yeteneği olarak tanımlamaktadır (Ketels, 2010). Görüldüğü üzere rekabetin birden çok tanımı bulunmaktadır. Yukarıda ifade edildiği gibi rekabet temelde, aynı amacı güden ekonomik birimler arasında zaman içinde ortaya çıkan bir yarışmadır. Günümüzde rekabet gücü, ülkelerin uluslararası ekonomik arenada söz sahibi olabilmeleri için çok önem verdiği konulardan biridir.

\section{Materyal ve Yöntem}

Ağaç ve ağaç mamulleri imalatı orman ürünleri sanayisinin alt sektörüdür. Ağaç ve ağaç mamulleri imalatı kendi içerisinde kereste ve parke, kaplama ve kontrplak, yonga ve lif levha olmak üzere alt sektörlerden oluşmaktadır. Çalışmada ağaç ve ağaç mamulleri imalatı bir bütün olarak ele alınmıştır. Çalışmada Uyumlaştırılmış (Armonize) Mal Tanım ve Kodlama sisteminin iki haneli sınıflandırması dikkate alınmıştır. HS sisteminde ağaç ve ağaç mamullerinin kod numarası 44'dür. Çalışma 2001-2015 dönemini kapsamakta olup, ihracat ve ithalat verileri BM Comtrade veri tabanından derlenmiştir.

Bu çalışmada karşılaştırmalı üstünlüğün ölçümünde Açıklanmış Karşılaştırmalı Üstünlükler, Açıklanmış Simetrik Karşılaştırmalı Üstünlükler ve Ticaret Dengesi İndeksi kullanılmıştır. Açıklanmış Karşılaştırmalı Üstünlükler (AKÜ) indeksi ilk kez Liesner tarafından ortaya atılmış, daha sonra ise Bela Balassa tarafından yeniden tanımlanarak geliştirilmiş, bu nedenle Balassa indeksi olarak da adlandırılmaktadır. Balassa geliştirdiği AKÜ indeksini ilk kez 1965 yılında yayınlamış olduğu çalışmasında kullanmıştır. AKÜ indeksi uluslararası ticarette uzmanlaşmayı ölçme konusunda birçok araştırmada kullanılmaktadır (Laursen, 1998). AKÜ İndeksi, bir malın veya sektörün ülkenin toplam ihracatındaki payı ile söz konusu malın veya sektörün dünyanın toplam ihracatındaki payı arasındaki orandır. AKÜ yaklaşımında ticaret sonrası verilere dayalı olarak ölçüm yapılmakta ve uluslararası ticaretin ürün bileşiminin ülkeler arasındaki göreli maliyetler kadar fiyat dışı faktörleri de yansıttığı varsayılmaktadır. $\mathrm{Bu}$ varsayım, ticareti yapan ülkeler arasındaki karşılaştırmalı üstünlükleri 'açıklamak' amacı ile yapılmaktadır (Eroğlu ve Özdamar, 2006). AKÜ indeksi hangi sektörlerin avantaj ya da dezavantajlı olduğunu saptamak konusunda en uygulanabilir yaklaşımlardan biridir. Bununla birlikte AKÜ indeksi kolayca hesaplanabilir olması nedeniyle bilimsel çalışmalarda sık sık kullanılmaktadır (Oelgemöller, 2012; Saray ve Hark, 2015). Balassa'nın AKÜ indeksi aşağıdaki şekilde formüle edilmektedir: 


$$
A K \ddot{U}_{i j}=\left[\left(\frac{X_{i j}}{X_{i t}}\right) /\left(\frac{X_{w j}}{X_{w t}}\right)\right]
$$


$\mathrm{X}_{\mathrm{ij}} i$ ülkesinin $j$ sektörünün ihracatını, $\mathrm{X}_{\mathrm{jt}} i$ ülkesinin toplam ihracatını, $\mathrm{X}_{\mathrm{wj}} j$ sektörü dünya ihracatını ve $X_{w t}$ toplam dünya ihracatını göstermektedir. AKÜ indeksi 0 ile $+\infty$ arasında bir değer almaktadır. Eğer indeks değeri birden büyükse o ülkenin ilgili sektörde karşılaştırmalı üstünlüğe sahip olduğu söylenir. Başka bir deyişle, o endüstrinin ülkenin toplam ihracat1 içindeki payı, dünya ticaretindeki payından daha büyüktür. Eğer indeks değeri birden az ise ülkenin ilgili sektörde karşılaştırmalı dezavantaja sahip olduğu söylenir (Mushanyuri ve Mzumara, 2013; Yasmin ve Altaf, 2014). Bununla beraber, eğer AKÜ $>4$ ise güçlü bir karşılaştırmalı üstünlük; $2<\mathrm{AKÜ}<4$ orta derecede karşılaştırmalı üstünlük; $1<\mathrm{AKÜ}<2$ zayıf bir karşılaştırmalı üstünlük; $0<\mathrm{AKÜ}<1$ ise karşılaş̧ırmalı dezavantaj söz konusudur (Hinloopen ve Marrewijk, 2001).

Çalışmada kullanılan ikinci bir ölçüt Açıklanmış Simetrik Karşılaştırmalı Üstünlükler (ASKÜ) indeksidir. ASKÜ indeksi şu şekilde formüle edilmektedir:

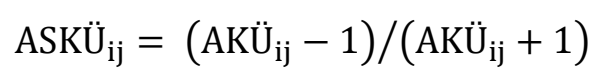

ASKÜ indeksi -1 ile +1 arasında bir değer almaktadır. Eğer indeks değeri pozitif ise ülke o üründe karşılaştırmalı üstünlüğe sahiptir. Eğer indeks değeri negatif ise ülke o ürünün ticaretinde karşılaştırmalı dezavantaja sahiptir (Laursen, 1998).

Rekabet gücünün ölçümünde kullanılan bir diğer ölçüt de Ticaret Dengesi İndeksidir (TDİ). Lafay tarafından geliştirilen bu indeks bir ülkenin ilgili üründe net ihracatçı veya net ithalatçı olup olmadığını belirlemek için kullanılmaktadır (Widodo, 2008; Ishchukova ve Smutka, 2013). İndeks şu şekilde formüle edilmektedir:

$$
\mathrm{TDI}_{\mathrm{ij}}=\left(\mathrm{X}_{\mathrm{ij}}-\mathrm{M}_{\mathrm{ij}}\right) /\left(\mathrm{X}_{\mathrm{ij}}+\mathrm{M}_{\mathrm{ij}}\right)
$$

(3)

Eşitlik 3'de 'i' ülkeyi, 'j' ürünü, ' $X$ ' ihracatı, ' $M$ ' ithalatı göstermektedir. TDİ indeksi -1 ile +1 arasında bir değer almaktadır. Eğer indeks değeri +1 ise ülkenin net ihracatçı konumda olduğu söylenir. Buna karşın eğer indeks değeri -1 ise ülkenin net ithalatçı konumda olduğu 
söylenir. Eğer indeks değeri 0 ise ülkenin ihracat ve ithalat değerlerinin birbirine eşit olduğu söylenir (Ma, 2013; Altay Topçu ve Sümerli Sarı̈̈l, 2015).

Açıklanmış Simetrik Karşılaştırmalı Üstünlükler İndeksi ve Ticaret Dengesi İndeksi kullanılarak üretim haritası oluşturulmaktadır. Üretim haritası A, B, C, D olarak dört gruptan oluşmaktadır. Bu gruplar aşağıdaki gibi açıklanabilir (Widodo, 2008):

Grup A: Karşılaştırmalı Üstünlük-Net İhracatçı (ASKÜ>0, TDİ>0).

Grup B: Karşılaştırmalı Üstünlük-Net İthalatçı (ASKÜ>0, TDİ<0).

Grup C: Karşılaştırmalı Dezavantaj-Net İhracatçı (ASKÜ<0, TDİ>0).

Grup D: Karşılaştırmalı Dezavantaj-Net İthalatçı (ASKÜ<0, TDI்<0).

\section{Bulgular}

Ağaç ve ağaç mamulleri endüstrisi yarattığı katma değer, istihdam ve ihracat olanakları ile üretici ülkeler adına artı değer yaratmaktadır. Dünya nüfusundaki hızlı artış, nüfusun gelir ve yaşam koşullarındaki iyileşmeler ağaç ve ağaç mamullerine olan talebin artmasında etkili faktörler olarak karşımıza çıkmaktadır. 2015 yılında dünya ağaç ve ağaç mamulleri pazarının büyüklüğü 257 milyar dolara ulaşmıştır. Aynı yılda İhracat 126 milyar dolar ve ithalat 131 milyar dolar olarak gerçekleşmiştir. Şekil 1'den de görüldüğü üzere 2009 yılında küresel ağaç ve ağaç mamulleri ihracatında sert bir düşüş göze çarpmaktadır. 2009 yılında dünya ağaç ve ağaç mamulleri ihracatı bir önceki yıla göre $\% 22$ oranında azalarak 117 milyar dolardan 91 milyar dolara gerilemiştir. Burada 2007 yılının ortalarından itibaren hissedilmeye başlanan ve 2008 yılında bütün dünyayı saran küresel ekonomik krizin önemli ölçüde etkili olduğu söylenebilir. Nitekim ekonomik krizin etkisiyle birlikte dünya ticareti \%12 oranında daralma göstermiştir (Hepaktan, 2010). Dünya ağaç ve ağaç mamulleri endüstrisinin de küresel krizden olumsuz etkilendiği açıkça görülmektedir. Ancak, izleyen y1llarda küresel piyasalarda yaşanan olumlu gelişmeler sonucu ihracat tekrar yükselmeye başlamış ve en yüksek seviyesine 141 milyar dolar ile 2014 yılında ulaşmıştır. 2015 yılında ise dünya ağaç ve ağaç mamulleri ihracatı bir önceki y1la göre $\% 10$ oranında azalmıştır. Küresel ekonomik krizin etkilerini henüz atlatamayan Avrupa ekonomilerindeki yavaşlama ve dış pazarlardaki zayıf görünüm nedeniyle küresel ağaç ve ağaç mamulleri ihracatının önümüzdeki yıllarda da yavaşlayacağı düşünülmektedir. 




Şekil 1. Dünya Ağaç ve Ağaç Mamulleri Ticaretinin Yıllara Göre Değişimi

2015 yılı itibariyle dünya ağaç ve ağaç mamulleri ihracatında öne çıkan ülkeler ile ilgili bilgiler Tablo 1'de sunulmaktadır. Dünya ağaç ve ağaç mamulleri ürünleri ihracatında Çin ilk sırada yer almaktadır. 2015 yılında Çin 14,2 milyar dolarlık ihracat gerçekleştirmiş ve bu dünya ağaç ve ağaç mamulleri ihracatının \%11,25'ine tekabül etmektedir. Çin'i sırasıyla 11,7 milyar dolarla Kanada, 8,9 milyar dolarla ABD, 7,8 milyar dolarla Almanya ve 6,3 milyar dolarla Rusya izlemektedir. Tablo 2'den de görüldügü üzere Nordik ülkelerinden İsveç ile Finlandiya dünyanın en fazla ağaç ve ağaç mamulleri ihracatı yapan ilk 20 ülke arasında yer almaktadır.

Tablo 1. Dünya Ağaç ve Ağaç Mamulleri İhracatında Öne Çıkan Ülkeler (2015)

\begin{tabular}{|c|c|c|c|c|c|c|c|}
\hline Sira & Ülkeler & $\begin{array}{l}\text { İhracat } \\
\text { Değeri } \\
\text { (Mln \$) }\end{array}$ & $\begin{array}{l}\text { Pay } \\
(\%)\end{array}$ & Sira & Ülkeler & $\begin{array}{l}\text { İhracat } \\
\text { Değeri } \\
\text { (Mln \$) }\end{array}$ & $\begin{array}{l}\text { Pay } \\
(\%)\end{array}$ \\
\hline 1 & Çin & 14.211 & 11,25 & 11 & Filipinler & 2.907 & 2,30 \\
\hline 2 & Kanada & 11.765 & 9,32 & 12 & Finlandiya & 2.789 & 2,21 \\
\hline 3 & $\mathrm{ABD}$ & 8.927 & 7,07 & 13 & Fransa & 2.589 & 2,05 \\
\hline 4 & Almanya & 7.866 & 6,23 & 14 & Belçika & 2.502 & 1,98 \\
\hline 5 & Rusya & 6.313 & 5,00 & 15 & Vietnam & 2.477 & 1,96 \\
\hline
\end{tabular}




\begin{tabular}{llll|llll}
\hline 6 & Avusturya & 4.351 & 3,45 & 16 & Yeni Zelanda & 2.468 & 1,95 \\
7 & Endonezya & 4.005 & 3,17 & 17 & Brezilya & 2.271 & 1,80 \\
8 & İsveç & 3.828 & 3,03 & 18 & Şili & 2.254 & 1,79 \\
9 & Malezya & 3.764 & 2,98 & 19 & Tayland & 2.134 & 1,69 \\
10 & Polonya & 3.718 & 2,94 & 20 & Çek Cum. & 1.891 & 1,50 \\
\hline
\end{tabular}

Kaynak: COMTRADE veri tabanı

Tablo 2'den de görüldüğü üzere, Çin, ABD ve Japonya en büyük ithalatçı ülkelerdir. 2015 yılında Çin 18,6 milyar dolar değerinde ağaç ve ağaç mamulleri ithal ederken, bunu sirasıyla 17,9 milyar dolar ithalatla ABD, 10 milyar dolar ithalatla Japonya, 8 milyar dolar ithalatla Almanya takip etmektedir. Tablo 2 incelendiğinde Nordik ülkelerinden İsveç, Finlandiya ve Norveç'in dünya ağaç ve ağaç mamulleri ithalatında ilk 20 'de yer aldıkları görülmektedir.

Tablo 2. Dünya Ağaç ve Ağaç Mamulleri İthalatında Öne Çıkan Ülkeler (2015)

\begin{tabular}{|c|c|c|c|c|c|c|c|}
\hline Sira & Ülkeler & $\begin{array}{l}\text { İhracat } \\
\text { Değeri (Mln } \\
\text { \$) }\end{array}$ & $\begin{array}{l}\text { Pay } \\
(\%)\end{array}$ & Sira & Ülkeler & $\begin{array}{l}\begin{array}{l}\text { İhracat } \\
\text { Değeri }\end{array} \\
(\mathrm{Mln} \$) \\
\end{array}$ & $\begin{array}{l}\text { Pay } \\
(\%)\end{array}$ \\
\hline 1 & Çin & 18.627 & 14,14 & 11 & Belçika & 2.726 & 2,07 \\
\hline 2 & $\mathrm{ABD}$ & 17.999 & 13,66 & 12 & Avusturya & 2.588 & 1,97 \\
\hline 3 & Japonya & 10.051 & 7,63 & 13 & Hindistan & 2.434 & 1,85 \\
\hline 4 & Almanya & 8.025 & 6,09 & 14 & İsviçre & 1.833 & 1,39 \\
\hline 5 & İngiltere & 6.916 & 5,25 & 15 & İsveç & 1.695 & 1,29 \\
\hline 6 & İtalya & 4.243 & 3,22 & 16 & Danimarka & 1.648 & 1,25 \\
\hline 7 & Fransa & 3.714 & 2,82 & 17 & Meksika & 1.628 & 1,24 \\
\hline 8 & Hollanda & 3.157 & 2,40 & 18 & Avustralya & 1.583 & 1,20 \\
\hline 9 & G. Kore & 3.111 & 2,36 & 19 & Norveç & 1.380 & 1,05 \\
\hline
\end{tabular}




\begin{tabular}{|c|c|c|c|c|c|c|c|}
\hline 10 & Kanada & 3.009 & 2,28 & 20 & İspanya & 1.269 & 0,96 \\
\hline
\end{tabular}

Kaynak: COMTRADE veri tabanı

Yapılan çalışmada Nordik ülkelerinin ağaç ve ağaç mamulleri ihracatındaki karşılaştırmalı üstünlüğü açıklanmış karşılaştırmalı üstünlükler (AKÜ), açıklanmış simetrik karşılaştırmalı üstünlükler (ASKÜ) ve ticaret dengesi indeksleri (TDİ) kullanılarak analiz edilmiştir. Tablo 3'de ağaç ve ağaç mamulleri imalatında ele alınan ülkeler için AKÜ indeks değerleri yer almaktadır. Buna göre, Danimarka, İsveç ve Finlandiya ağaç ve ağaç mamulleri imalatında karşılaştırmalı üstünlüğe (rekabet gücüne) sahiptir. Söz konusu sektöre ait AKÜ indeks değeri 1'den büyüktür. Bununla birlikte, Finlandiya'nın üstünlük derecesi "güçlü” düzeyde iken $(\mathrm{AKÜ}>4)$, İsveç'in "orta derecede" $(2<\mathrm{AKU}<4)$ ve Danimarka'nın ise "zaylf" düzeydedir $(1<\mathrm{AKÜ}<2)$. Norveç ve İzlanda ise ağaç ve ağaç mamulleri imalatında karşılaştırmalı dezavantaja sahiptir $(0<\mathrm{AKÜ}<1)$. Analiz sonucunda dikkat çeken bir diğer husus da incelenen dönemde Finlandiya ile İsveç'in AKÜ indeks değerleri artarken, Danimarka'nın AKÜ indeks değerinin azaldığıdır.

Tablo 3. Ağaç ve Ağaç Mamullerine Ait AKÜ Değerleri

\begin{tabular}{llllll}
\hline Yıllar & Danimarka & İsveç & Norvec & Finlandiya & İzlanda \\
\hline 2001 & 1,25 & 3,29 & 0,51 & 4,84 & 0,02 \\
2002 & 1,18 & 3,36 & 0,54 & 4,95 & 0,00 \\
2003 & 1,21 & 3,37 & 0,52 & 5,22 & 0,01 \\
2004 & 1,18 & 3,01 & 0,46 & 4,92 & 0,01 \\
2005 & 1,12 & 3,16 & 0,41 & 4,69 & 0,02 \\
2006 & 1,17 & 3,44 & 0,42 & 4,69 & 0,03 \\
2007 & 1,21 & 3,66 & 0,44 & 4,92 & 0,02 \\
2008 & 1,34 & 3,67 & 0,39 & 4,72 & 0,01 \\
2009 & 1,21 & 4,08 & 0,45 & 4,82 & 0,03 \\
2010 & 1,11 & 3,90 & 0,46 & 5,32 & 0,03 \\
2011 & 1,04 & 3,65 & 0,44 & 5,49 & 0,01 \\
\hline
\end{tabular}




\begin{tabular}{lccccc}
\hline 2012 & 0,99 & 3,85 & 0,47 & 5,85 & 0,02 \\
2013 & 1,10 & 3,77 & 0,51 & 6,06 & 0,01 \\
2014 & 1,09 & 3,79 & 0,57 & 6,01 & 0,01 \\
2015 & 1,05 & 3,58 & 0,72 & 6,10 & 0,01 \\
\hline
\end{tabular}

Kaynak: COMTRADE verileri kullanılarak yazar tarafından hesaplanmıştır

Tablo 4'de Açıklanmış Simetrik Karşılaştırmalı Üstünlükler indeksine göre rekabet gücü değerleri yer almaktadır. Ağaç ve ağaç mamulleri imalatında karşılaştırmalı üstünlüğe (rekabet gücüne) sahip olan ülkeler arasında Danimarka, İsveç ve Finlandiya bulunmaktadır. Buna karşın Norveç ile İzlanda'nın karşılaştırmalı üstünlüğe sahip olmadıkları görülmüştür. Tablo 4'de görüldüğü üzere, Finlandiya'nın ağaç ve ağaç mamulleri imalatında rekabet gücü diğer ülkelere göre daha yüksektir. Bunu sırasıyla İsveç ve Danimarka takip etmektedir.

Tablo 4. Ağaç ve Ağaç Mamullerine Ait ASKÜ Değerleri

\begin{tabular}{llllll}
\hline Yıllar & Danimarka & İsveç & Norveç & Finlandiya & İzlanda \\
\hline 2001 & 0,11 & 0,53 & $-0,32$ & 0,66 & $-0,96$ \\
2002 & 0,08 & 0,54 & $-0,30$ & 0,66 & $-1,00$ \\
2003 & 0,09 & 0,54 & $-0,31$ & 0,68 & $-0,98$ \\
2004 & 0,08 & 0,50 & $-0,37$ & 0,66 & $-0,99$ \\
2005 & 0,06 & 0,52 & $-0,42$ & 0,65 & $-0,97$ \\
2006 & 0,08 & 0,55 & $-0,41$ & 0,65 & $-0,95$ \\
2007 & 0,10 & 0,57 & $-0,39$ & 0,66 & $-0,96$ \\
2008 & 0,14 & 0,57 & $-0,44$ & 0,65 & $-0,98$ \\
2009 & 0,10 & 0,61 & $-0,38$ & 0,66 & $-0,93$ \\
2010 & 0,05 & 0,59 & $-0,37$ & 0,68 & $-0,95$ \\
2011 & 0,02 & 0,57 & $-0,39$ & 0,69 & $-0,98$ \\
\hline
\end{tabular}




\begin{tabular}{llllll}
\hline 2012 & 0,00 & 0,59 & $-0,36$ & 0,71 & $-0,97$ \\
2013 & 0,05 & 0,58 & $-0,33$ & 0,72 & $-0,98$ \\
2014 & 0,04 & 0,58 & $-0,28$ & 0,71 & $-0,97$ \\
2015 & 0,02 & 0,56 & $-0,17$ & 0,72 & $-0,98$ \\
\hline
\end{tabular}

Kaynak: COMTRADE verileri kullanılarak yazar tarafından hesaplanmıştır

Ele alınan ülkelerin Ticaret Dengesi İndeks sonuçları Tablo 5'de sunulmuştur. Buna göre, İsveç ve Finlandiya ağaç ve ağaç mamulleri imalatında net ihracatçı ülke konumundadır. Bununla birlikte, söz konusu ülkelerin TDİ değerlerinde genel olarak bir azalma göze çarpmaktadır. Hesaplanan TDİ sonuçlarına göre Danimarka, Norveç ve İzlanda'nın ağaç ve ağaç mamulleri imalatı alt sektöründe net ithalatçı ülkeler olduğu görülmektedir. Nitekim bu ülkelere ait TDİ değerleri söz konusu dönemde negatif bir değer almıştır.

Tablo 5. Ağaç ve Ağaç Mamullerine Ait TDİ Değerleri

\begin{tabular}{llllll}
\hline Yıllar & Danimarka & İsveç & Norveç & Finlandiya & İzlanda \\
\hline 2001 & $-0,21$ & 0,46 & $-0,41$ & 0,53 & $-0,98$ \\
2002 & $-0,22$ & 0,48 & $-0,40$ & 0,52 & $-1,00$ \\
2003 & $-0,26$ & 0,46 & $-0,45$ & 0,50 & $-0,99$ \\
2004 & $-0,27$ & 0,43 & $-0,48$ & 0,47 & $-1,00$ \\
2005 & $-0,31$ & 0,42 & $-0,51$ & 0,39 & $-0,99$ \\
2006 & $-0,34$ & 0,48 & $-0,48$ & 0,43 & $-0,98$ \\
2007 & $-0,36$ & 0,41 & $-0,55$ & 0,37 & $-0,99$ \\
2008 & $-0,30$ & 0,38 & $-0,57$ & 0,21 & $-0,99$ \\
2009 & $-0,30$ & 0,46 & $-0,54$ & 0,43 & $-0,96$ \\
2010 & $-0,37$ & 0,41 & $-0,56$ & 0,38 & $-0,97$ \\
2011 & $-0,41$ & 0,35 & $-0,56$ & 0,39 & $-0,98$ \\
\hline
\end{tabular}




\begin{tabular}{llllll}
\hline 2012 & $-0,44$ & 0,37 & $-0,54$ & 0,41 & $-0,98$ \\
2013 & $-0,37$ & 0,36 & $-0,51$ & 0,44 & $-0,99$ \\
2014 & $-0,37$ & 0,37 & $-0,46$ & 0,50 & $-0,99$ \\
2015 & $-0,37$ & 0,39 & $-0,41$ & 0,54 & $-0,99$ \\
\hline
\end{tabular}

Kaynak: COMTRADE verileri kullanılarak yazar tarafından hesaplanmıştır

Tablo 6'da ele alınan ülkelerin ağaç ve ağaç mamulleri imalatının üretim haritası yer almaktadır. Araştırma bulgularına göre Finlandiya ile İsveç ağaç ve ağaç mamulleri imalatında A grubunda yer almaktadır. Buna göre, İsveç ve Finlandiya ele alınan sektörde karşılaştırmalı üstünlük-net ihracatçı konumdadır. Danimarka ele alınan sektörde karşılaştırmalı üstünlük-net ithalatçı konumdadır (B grubu). Norveç ile İzlanda ise D grubunda yer almaktadır. $\mathrm{Bu}$ da bu iki ülkenin ağaç ve ağaç mamulleri imalatında karşılaştırmalı dezavantaj-net ithalatçı konumda olduğunu göstermektedir.

Tablo 6. Ağaç ve Ağaç Mamullerine Ait Üretim Haritası

\begin{tabular}{llllll}
\hline Yıllar & Danimarka & İsveç & Norveç & Finlandiya & İzlanda \\
\hline 2001 & B & A & D & A & D \\
2002 & B & A & D & A & D \\
2003 & B & A & D & A & D \\
2004 & B & A & D & A & D \\
2005 & B & A & D & A & D \\
2006 & B & A & D & A & D \\
2007 & B & A & D & A & D \\
2008 & B & A & D & A & D \\
2009 & B & A & D & A & D \\
2010 & B & A & D & A & D \\
2011 & B & A & D & A & D
\end{tabular}




\begin{tabular}{llllll}
\hline 2012 & B & A & D & A & D \\
2013 & B & A & D & A & D \\
2014 & B & A & D & A & D \\
2015 & B & A & D & A & D \\
\hline
\end{tabular}

Kaynak: COMTRADE verileri kullanılarak yazar tarafından hesaplanmıştır

Not: Grup A: Karşılaştırmalı Üstünlük-Net İhracatçı, Grup B: Karşılaştırmalı Üstünlük-Net İthalatçı, Grup C: Karşılaştırmalı Dezavantaj-Net İhracatçı, Grup D: Karşılaştırmalı Dezavantaj-Net İthalatçı.

\section{Sonuç}

Yirminci yüzyılın son çeyreğinden itibaren hız kazanan küreselleşme dünya ticaretinde önemli değişimlere yol açmıştır. Küreselleşme ile birlikte dünya ticaretinin önündeki engeller büyük ölçüde kalkmış ve uluslararası pazarlarda başarının anahtarı rekabet gücü olmuştur. Bugün dünya ticaretinde yoğun bir rekabet süreci yaşanmakta ve bu süreç bütün sektörler ile birlikte ormancılık sektörünü de etkilemektedir. Dolayısıyla dünya orman ürünleri pazarında rekabetçi üstünlük sağlayan ülkeler dünya ticaretinde ön sıralara yükselmektedir.

Bu çalışmada Nordik ülkeleri olan Danimarka, İsveç, Norveç, Finlandiya ve İzlanda'nın ağaç ve ağaç mamulleri imalatındaki karşılaştırmalı üstünlüğü incelenmiştir. Çalışmada HS iki basamaklı sınıflandırma düzeyi dikkate alınmıştır. Verilerin analizinde Açıklanmış Karşılaştırmalı Üstünlükler, Açıklanmış Simetrik Karşılaştırmalı Üstünlükler ve Ticaret Dengesi İndeksi kullanılmıştır. Araştırma bulguları genel olarak değerlendirildiğinde Nordik ülkelerinden Finlandiya ile İsveç'in ağaç ve ağaç mamulleri ihracatında daha güçlü bir rekabetçi yapıya sahip olduğu görülmektedir. Ayrıca, bu iki ülkenin söz konusu sektördeki rekabet güçlerinin de giderek artış gösterdiği saptanmıştır. Danimarka ele alınan sektörde karşılaştırmalı üstünlüğe sahip olmasına rağmen, rekabet gücünün zayıf olduğu görülmüştür. Norveç ve İzlanda ise ağaç ve ağaç mamulleri imalatında karşıllaştırmalı dezavantaja sahip olduğu saptanmıştır. Bununla birlikte, Finlandiya ile İsveç'in ele alınan sektörde karşılaştırmalı üstünlük-net ihracatçı konumda oldukları belirlenmiştir. Buna karşın Danimarka karşılaştırmalı üstünlük-net ithalatçı konumdadır. Norveç ile İzlanda ise karşılaştırmalı dezavantaj-net ithalatçı konumdadırlar.

Ağaç ve ağaç mamulleri imalatı ekonomiye sağladığı katkılarından dolayı Nordik ülkelerinin ekonomik gelişmesinde önemli rol üstlenmektedir. Nordik ülkeleri sahip olduğu doğal kaynaklarıyla, teknoloji ve kalifiyeli işgücü ile dünya ağaç ve ağaç mamulleri piyasasında rekabet edebilir niteliktedir. Söz konusu ülkelerin küresel piyasadaki payının arttırılması için uluslararası standartlara ve tüketici tercihlerine uygun yüksek kaliteli ürünlerin küresel piyasalara sunulması gerekmektedir. Bununla birlikte, ürün çeşitlemesine gidilerek küresel 
pazarlarda talep edilen ürünlerin üretilmesi rekabet açısından da oldukça önem arz etmektedir. 


\section{Kaynaklar}

AINI, Z.N., RODA, J.M., FAUZI, P.A. (2010). Comparative Advantage of Malaysian Wood Products in the European Market, National Postgraduate Seminar (6-7 July 2010), Kuala Lumpur, Malaysia.

ALTAY TOPÇU, B., SÜMERLİ SARIGÜL, S. (2015). Comparative Advantage and the Products Mapping of Exporting Sectors in Turkey, Akademik Sosyal Araştırmalar Dergisi, 3(18), 330-348.

BASHIMOV, G. (2015). Rusya Orman Ürünleri Sanayisinin İhracat Yapıs1 ve Rekabet Gücü, Bitlis Eren Üniversitesi Sosyal Bilimler Enstitüsü Dergisi, 4(2), 125-134.

ÇOBAN, O. (2001). Türkiye Tekstil Endüstrisinin Üretim Yapısı ve Karşılaştırmalı Rekabet Gücü, Doktora Tezi, Cumhuriyet Üniversitesi Sosyal Bilimler Enstitüsü, Sivas.

ERKAN, B., ARPACI, B.B., YARALI, F., GÜVENÇ, İ. (2015). Türkiye'nin Sebze İhracatında Karşılaştırmalı Üstünlükleri, KSÜ Doğa Bilimleri Dergisi, 18(4), 70-76.

EKTİ, E. (2013). Endüstriyel Orman Ürünleri. Doğu Marmara Kalkınma Ajansı.

EROĞLU, Ö., ÖZDAMAR, G. (2006). Türk İmalat Sanayinin Rekabet Gücü ve Beyaz Eşya Sektörü Üzerine Bir İnceleme, Akdeniz İ.I.B.F. Dergisi, 11, 85-104.

GONUGUNTLA, S. (2007). New Zealand Forestry: An Analysis of Comparative Advantage, NZ Journal of Forestry, 51(4), 21-27.

HEPAKTAN, E. (2010). 2008 Ekonomik Krizinin Türkiye'nin Dış Ticaretine Yansımaları, Uluslararas1 Sempozyum V. Küresel Kriz Sonrasında Ekonominin Yeniden Yapılanmas1, (27-29 Mayıs), Balıkesir, Türkiye.

HINLOOPEN, J., MARREWIJK, C.V. (2001). On the Empirical Distribution of the Balassa Index, Review of World Economics, 137(1), 1-35.

ISHCHUKOVA, N., SMUTKA, L. (2013). Comparative Advantage: Products Mapping of the Russian Agricultural Exports, Agris on-line Papers in Economics and Informatics, 5(3), 13-24.

KELLECİ, S. (2009). Avrupa Birliği'ne Giriş Sürecinde Türkiye'nin Rekabet Gücü: Karşılaştırmalı Üstünlükler Modeline Göre Sektörel Bir Analiz, Doktora Tezi, Adnan Menderes Üniversitesi Sosyal Bilimler Enstitüsü, Aydın.

KETELS, C.H.M. (2010). Export Competitiveness: Reversing the Logic, Institute for Strategy and Competitiveness, Harvard Business School, Boston.

LAURSEN, K. (1998). Revealed Comparative Advantage and the Alternatives as Measures of International Specialization, Danish Research Unit for Industrial Dynamics (DRUID) Working Paper No: 98-30.

MA, A.S. (2013). Revealed Comparative Advantage Measure: ASEAN-China Trade Flows, Journal of Economics and Sustainable Development, 4(7), 136-145.

MAKSYMETS, O., LÖNSTEDT, L. (2015). Trends in Markets for Forest Based Products and Consequences for Selected Countries. Open Journal of Forestry, 5, 697-710.

MARKUSEN, J. (1992). Productivity, Competitiveness, Trade Performance and Real Income: The Nexus among Four Concepts, Supply and Services Canada, Ottawa 
MUSHANYURI, B.E., MZUMARA, M. (2013). An Assessment of Comparative Advantage of Mauritius. European Journal of Sustainable Development, 2(3), 35-42.

MÜFTÜOĞLU, G.İ. (2011). Ormana Dayalı Sektörlerin Dış Ticarette Rekabet Gücü. Yüksek Lisans Tezi, Düzce Üniversitesi Fen Bilimleri Enstitüsü, Düzce.

OELGEMÖLLER, J. (2012). Analyzing the International Competitiveness of the Industry in Portugal, Ireland, Greece and Spain using Revealed Comparative Advantages (RCA) Indicators, CAWM Discussion Paper No: 61, University of Münster.

PALUS, H., PAROBEK, J., LIKER, B. (2015). Trade Performance and Competitiveness of the Slovak Wood Processing Industry within the Visegrad Group Countries. Drvna Industrija, 66(3), 195-203.

SARAÇOĞLU, B., KÖSE, N. (2000). Bazı Gıda Sanayilerinin Uluslararası Rekabet Gücü: Makarna, Bisküvi ve Un Sanayi. TEAE Yayın No: 39, Ankara.

SARAY, M.O., HARK, R. (2015). OECD Ülkelerinin İleri-Teknoloji Ürünlerindeki Rekabet Güçlerinin Değerlendirilmesi. Çankırı Karatekin Üniversitesi İktisadi ve İdari Bilimler Fakültesi Dergisi, 5(1), 347-372.

SEYİOĞLU, H. (2015). Uluslararası İktisat: Teori, Politika ve Uygulama, Geliştirilmiş (20. Bs.). Güzem Can Yayınları, İstanbul.

UN COMTRADE. 2017. http://comtrade.un.org/

WIDODO, T. (2008). Shift in Comparative Advantage, Dynamic Market and Purchasing Power Parity in the East Asia, Doctoral Thesis, Graduate School of Economics Hiroshima University of Economics, Hiroshima, Japan.

YASMIN, B., ALTAF, S. (2014). Revealed Comparative Advantage of Carpets and Textile Floor Covering Industry in Pakistan, India and China, Journal of Economic Cooperation and Development, 35(4), 113-134.

YILDIRIM, İ. (2006). Orman Endüstrisine Ait Bazı Ürün Gruplarının Avrupa Birliği Sürecinde Rekabet Edebilirliğinin İncelenmesi, Yüksek Lisans Tezi, Karadeniz Teknik Üniversitesi Fen Bilimleri Enstitüsü, Trabzon.

YILDIRIM, İ., AKYÜZ, K.C., GEDİK, T., BALABAN, Y., ÇABUK, Y. (2008). Türkiye Ahşap Levha Endüstrisinin Avrupa Birliği Ülkeleri ile Rekabet Edebilirliği, Bartın Orman Fakültesi Dergisi, 10(13), 11-22. 